\title{
Prospective Evaluation of the Effect of Short-Term Oral Vitamin D Supplementation on Peripheral Neuropathy in Type 2 Diabetes Mellitus
}

\author{
D. Shehab ${ }^{a} \quad K^{2}$ haled Al-Jarallah ${ }^{a} \quad$ Nabila Abdella $^{a}$ Olusegun A. Mojiminiyi ${ }^{b}$ \\ Hisham Al Mohamedy ${ }^{c}$ \\ Departments of a Medicine and ${ }^{\mathrm{b}}$ Pathology, Faculty of Medicine, Kuwait University, and ${ }^{\mathrm{c}}$ Department of Medicine, \\ Mubarak Al-Kabeer Hospital, Jabriya, Kuwait
}

\section{Key Words}

Clinical trial · Peripheral neuropathy · Type 2 diabetes ·

Vitamin D

\begin{abstract}
Objective: We aimed to assess the efficacy of short-term oral vitamin $D$ supplementation on peripheral neuropathy in patients with type 2 diabetes. Materials and Methods: This prospective, placebo-controlled trial included 112 type 2 diabetic patients with diabetic peripheral neuropathy (DPN) and vitamin $\mathrm{D}[25(\mathrm{OH}) \mathrm{D}]$ deficiency. Patients were sequentially assigned to a treatment group $(n=57)$ and a placebo group ( $n=55)$. DPN was assessed using a neuropathy symptom score (NSS), a neuropathy disability score (NDS) and a nerve conduction study (NCS). Vitamin D status was determined by measuring the serum total $25(\mathrm{OH}) \mathrm{D}$ concentration. Patients received either oral vitamin $D_{3}$ capsules or starch capsules once weekly for 8 weeks. The primary outcome was changes in NSS and NDS from baseline. The secondary outcome was changes in the NCS result. Results: Serum $25(\mathrm{OH}) \mathrm{D}$ concentrations significantly improved after
\end{abstract}

oral vitamin $D$ supplementation in the treatment group when compared to the placebo group $(32.8 \pm 23.7$ vs. $1.1 \pm$ $3.6, p<0.0001)$. Similarly, the improvement in NSS values was significantly greater in the treatment group than in the placebo group $(-1.49 \pm 1.37$ vs. $-0.20 \pm 0.59, p<0.001)$. No improvement was observed for NDS and NCS between the 2 groups after treatment. Conclusion: Short-term oral vitamin $D_{3}$ supplementation improved vitamin $D$ status and the symptoms of neuropathy in patients with type 2 diabetes.

(c) 2015 S. Karger AG, Basel

\section{Introduction}

Diabetic neuropathy is a long-term complication of diabetes that can cause considerable morbidity in many patients, leading to a deterioration of their quality of life. Previously reported pathways relevant for the development of diabetic neuropathy include the glucose flux/ polyol pathway (aldolase reductase, sorbitol), the hexosamine pathway (fructose-6P), the accumulation of advanced glycation end-products and several other mecha-

Prof. D. Shehab

Faculty of Medicine, Kuwait University PO Box 24923

Jabriya, Safat 13110 (Kuwait)

E-Mail diaa@hsc.edu.kw 
Fig. 1. Flow chart.

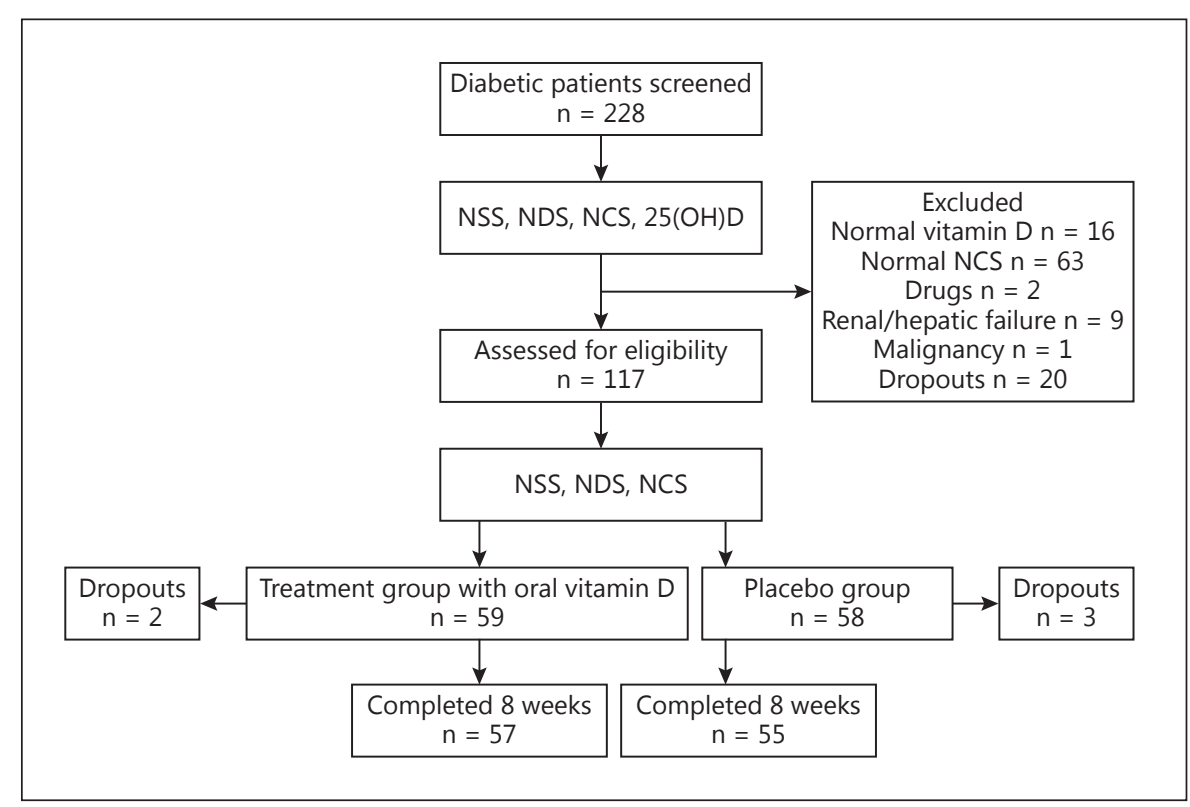

nisms [1]. A deficiency of vitamin D [25-hydroxyvitamin $\mathrm{D}, 25(\mathrm{OH}) \mathrm{D}]$ is common in patients with diabetes, and low concentrations are associated with the presence and the severity of sensory neuropathy in diabetes $[2,3]$. The mechanisms and pathophysiology of neuropathy are associated with hyperglycemia via microvascular injury or direct neuronal metabolic injury [2]. Vitamin D deficiency has been shown to be an independent risk factor for diabetic peripheral neuropathy (DPN) [3, 4]. Topical and oral vitamin $\mathrm{D}$ have been reported to significantly reduce the symptoms and pain of DPN [5-7]. However, no casecontrol clinical trials have been reported that demonstrate the efficacy of vitamin D supplementation on the symptoms of DPN. We hypothesized that correction of a vitamin $\mathrm{D}$ deficiency may directly or indirectly improve the symptoms of DPN. This study evaluated the potential efficacy of short-term oral vitamin D supplementation on neuropathy in patients with type 2 diabetes mellitus, making use of validated neuropathy assessment tools: a neuropathy symptom score (NSS), a neuropathy disability score (NDS) and electrophysiological studies, i.e. a nerve conduction study (NCS).

\section{Materials and Methods}

\section{Study Design}

This study involved an interventional, prospective, nonrandomized, double-blind, placebo-controlled clinical trial lasting 8 weeks. It assessed, by means of an NSS, an NDS and an NCS, the efficacy of vitamin D supplementation on subjective and objective neuropathic manifestations in patients. Patients who fulfilled the inclusion criteria were recruited by independent clinicians from hospital diabetology clinics (fig. 1), and were then allocated to the 2 arms of the intervention, i.e. treatment and placebo, according to a sequential order generated by the hospital recording system.

\section{Participants}

Exclusion Criteria

These included: patients with a nondiabetic cause for neuropathy such as inflammatory rheumatic diseases, malignancy, hyperparathyroidism, alcoholism, renal or liver failure or vitamin $\mathrm{B}_{12}$ deficiency, patients taking drugs that could cause peripheral neuropathy and patients with other causes for pain in the feet (peripheral arterial disease or infections).

\section{Inclusion Criteria}

Adult patients with type 2 diabetes with DPN and vitamin D deficiency were eligible. In total, 228 type 2 diabetic patients were screened over a 1-year period from March 2012 to March 2013; 111 were excluded (fig. 1), and of the remaining 117, 59 were assigned to treatment and 58 to placebo. Two patients dropped out of the treatment group and 3 out of the placebo group. So, 57 patients in the treatment group and 55 in the placebo group with DPN and vitamin $\mathrm{D}$ deficiency completed the study, i.e. a total of 112 patients (48 males and 68 females) with an age range of 38-80 years. Type 2 diabetes was defined as a fasting plasma glucose level $\geq 7.0$ $\mathrm{mmol} / \mathrm{l}$ on at least two occasions or glycated hemoglobin (HbAlc) $\geq 6.5 \%$ [8]. All patients attended regular follow-ups at the diabetic clinics of the Mubarak Al-Kabeer Hospital, Kuwait. A detailed history was recorded and a physical examination was conducted for all patients. Fasting blood glucose, renal, liver and lipid profiles and $\mathrm{HbAlc}$ were measured. The $25(\mathrm{OH}) \mathrm{D}$ level was also measured. Vitamin D deficiency was defined as a serum $25(\mathrm{OH}) \mathrm{D}$ con- 
Table 1. Demographic characteristics of type 2 diabetic subjects in the treatment and placebo groups at baseline

\begin{tabular}{|c|c|c|c|}
\hline Characteristics & $\begin{array}{l}\text { Treatment group } \\
(\mathrm{n}=57)\end{array}$ & $\begin{array}{l}\text { Placebo group } \\
(\mathrm{n}=55)\end{array}$ & $\begin{array}{l}\mathrm{p} \\
\text { value }\end{array}$ \\
\hline Gender & & & 0.190 \\
\hline Male & $21(36.8)$ & $27(49.1)$ & \\
\hline Female & $36(63.2)$ & $28(50.9)$ & \\
\hline Mean age $\pm S D$, years & $61.8 \pm 8.1$ & $59.8 \pm 9.6$ & 0.229 \\
\hline Range & $45-80$ & $38-78$ & \\
\hline Duration of diabetes & & & 0.116 \\
\hline$>10$ years & $44(77.2)$ & $35(63.6)$ & \\
\hline$<10$ years & $13(22.8)$ & $20(36.4)$ & \\
\hline Body mass index & & & 0.247 \\
\hline$<25$ & $8(14.0)$ & $4(7.3)$ & \\
\hline$>25$ & $49(86.0)$ & $51(92.7)$ & \\
\hline Retinopathy & & & 0.235 \\
\hline Positive & $20(46.5)$ & $12(33.3)$ & \\
\hline Coronary heart disease & & & 0.389 \\
\hline Positive & $16(32.7)$ & $10(24.4)$ & \\
\hline Stroke & & & 0.694 \\
\hline Positive & $2(3.6)$ & $1(2.3)$ & \\
\hline Treatment & & & 0.507 \\
\hline OHA only & $20(35.1)$ & $25(45.5)$ & \\
\hline Insulin only & $6(10.5)$ & $4(7.3)$ & \\
\hline Insulin + OHA & $31(54.4)$ & $26(47.3)$ & \\
\hline
\end{tabular}

Values denote $\mathrm{n}(\%)$, unless otherwise indicated. OHA = Oral hypoglycemic agent.

centration of $<50 \mathrm{nmol} / \mathrm{ml}$. Written informed consent was obtained from all participants. The study protocol was approved by the Ethics Committees, Faculty of Medicine, Kuwait University, and the Ministry of Health, in accordance with the provisions for human research in the Declaration of Helsinki. The study subjects were drawn from the general population living in Kuwait, a geographic region which is sunny all the year round and where the majority of citizens have a dress code of covering up.

\section{Study Outcomes}

The primary outcome measures were the assessment of neuropathy using an NSS and an NDS. The NSS includes symptoms of neuropathy (the nature of pain, the location, the duration and the measures undertaken to alleviate symptoms). Generally, the NSS values ranged from 0 to 9 , and a value $>5$ was defined as neuropathy. The NDS includes ankle reflex, vibration, pinprick and temperature; its values ranged from 0 to 10 , and a value $>6$ was defined as neuropathy [3, 9-11].

The secondary outcome measure was the assessment of neuropathy by means of an NCS, performed on all patients using established, standard techniques $[12,13]$. Measurements of latencies, amplitudes and conduction velocities were evaluated using previously established cut-off values, for the motor (peroneal, tibial, median and ulnar) and sensory (sural, median and ulnar) nerves $[3,14,15]$.

The clinical assessment of peripheral neuropathy at baseline and after treatment was conducted for all patients by a single clini- cian (D.S.) who was blinded to the treatment choice. Thus in this study, type 2 diabetic patients who had an NSS $>5$ and an NDS $>6$, in addition to an abnormal NCS, were categorized as having DPN.

\section{Serum Vitamin D Status}

Vitamin D status was determined at baseline and after treatment by measuring serum total $25(\mathrm{OH}) \mathrm{D}$ concentrations using radioimmunoassay kits (DiaSorin, Stillwater, Minn., USA) according to the manufacturer's instructions. A serum $25(\mathrm{OH}) \mathrm{D}$ concentration $<50 \mathrm{nmol} / \mathrm{ml}$ was defined as a vitamin D deficiency [16].

\section{Intervention}

Concealed opaque envelopes were prepared for all study participants for allocation into the vitamin D treatment group or the placebo group. This was done under the direct control of a single investigator (H.M.). The treatment group received oral capsules of vitamin $\mathrm{D}_{3}$ (a capsule of cholecalciferol, 50,000 IU, Bronson, Lindon, Utah, USA) once weekly for 8 weeks [17]. The placebo group received starch capsules, also once weekly for 8 weeks. The study medications were visually indistinguishable from one another and were stored as advised by the manufacturers. The study participants and the outcome assessor were blinded to the treatment allocation once during the conclusion of the study. Primary and secondary outcome measures of all patients were reassessed after 8 weeks of intervention.

\section{Clinical Evaluation}

The primary end point was the difference between baseline and after treatment in the NSS and NDS, and the secondary end point was changes in the electrophysiological study, i.e. the NCS, between baseline and after treatment. Compliance with supplementation was evaluated by repeating laboratory tests. Indirect measures to improve the adherence to interventions included educating the patients and scheduling appointments.

\section{Statistical Analysis}

Data were analyzed using the Statistical Package for Social Sciences version 19.0 (SPSS Inc., Chicago, Ill., USA). Data are expressed as percentages or mean $\pm \mathrm{SD}$. Categorical variables were compared by $\chi^{2}$ test. The mean values of the continuous variables were compared using the independent-samples or paired-samples Student t test as appropriate. For skewed data, analysis was performed using the Mann-Whitney U test. The Spearman correlation coefficient was used to evaluate the correlation between the improvement in $25(\mathrm{OH}) \mathrm{D}$ and the NSS. Values of $\mathrm{p}<0.05$ were considered to be statistically significant.

\section{Results}

The demographic characteristics of the 2 groups at baseline are given in table 1 . There were no significant differences between the 2 groups regarding gender, age, duration of diabetes, body mass index, the complications of diabetes (retinopathy, coronary heart disease and stroke) or antidiabetic medications. The biochemical pa- 
Table 2. Metabolic parameters of the treatment and placebo groups at baseline (before treatment) and after treatment

\begin{tabular}{|c|c|c|c|}
\hline Parameters & $\begin{array}{l}\text { Treatment group } \\
(\mathrm{n}=57)\end{array}$ & $\begin{array}{l}\text { Placebo group } \\
(\mathrm{n}=55)\end{array}$ & $\begin{array}{l}\mathrm{p} \\
\text { value }\end{array}$ \\
\hline \multicolumn{4}{|l|}{ HbAlc, \% } \\
\hline Before & $9.2 \pm 2.2$ & $8.6 \pm 2.1$ & 0.840 \\
\hline After & $9.5 \pm 2.1$ & $8.9 \pm 2.1$ & 0.122 \\
\hline \multicolumn{4}{|c|}{ Creatinine, $\mu \mathrm{mol} / \mathrm{l}$} \\
\hline Before & $68.6 \pm 25.2$ & $70.7 \pm 23.8$ & 0.651 \\
\hline After & $69.3 \pm 27.7$ & $70.0 \pm 24.6$ & 0.858 \\
\hline \multicolumn{4}{|c|}{ Total cholesterol, mmol/l } \\
\hline Before & $4.5 \pm 1.1$ & $4.9 \pm 0.9$ & 0.600 \\
\hline After & $4.6 \pm 1.2$ & $4.7 \pm 1.1$ & 0.558 \\
\hline \multicolumn{4}{|c|}{ Triglycerides, mmol/l } \\
\hline Before & $1.6 \pm 0.9$ & $1.9 \pm 0.9$ & 0.080 \\
\hline After & $1.7 \pm 0.9$ & $1.9 \pm 0.9$ & 0.140 \\
\hline \multicolumn{4}{|c|}{$\mathrm{HDL}-\mathrm{C}, \mathrm{mmol} / \mathrm{l}$} \\
\hline Before & $1.1 \pm 0.1$ & $1.1 \pm 0.5$ & 0.090 \\
\hline After & $1.0 \pm 0.3$ & $1.0 \pm 0.3$ & 0.713 \\
\hline \multicolumn{4}{|c|}{ LDL-C, mmol/l } \\
\hline Before & $2.6 \pm 0.9$ & $2.8 \pm 1.9$ & 0.475 \\
\hline After & $2.7 \pm 0.9$ & $2.7 \pm 1.0$ & 0.816 \\
\hline \multicolumn{4}{|c|}{ Serum calcium, $\mathrm{mmol} / \mathrm{l}$} \\
\hline Before & $2.4 \pm 0.1$ & $2.5 \pm 0.2$ & 0.212 \\
\hline After & $2.3 \pm 0.09$ & $2.4 \pm 0.1$ & 0.223 \\
\hline \multicolumn{4}{|c|}{ Serum albumin, $g / l$} \\
\hline Before & $37.4 \pm 7.1$ & $38.4 \pm 7.9$ & 0.482 \\
\hline After & $37.8 \pm 6.0$ & $39.2 \pm 6.2$ & 0.226 \\
\hline \multicolumn{4}{|l|}{ AST, IU/1 } \\
\hline Before & $22.7 \pm 8.6$ & $25.5 \pm 10.8$ & 0.131 \\
\hline After & $23.8 \pm 10.9$ & $23.9 \pm 7.8$ & 0.954 \\
\hline \multicolumn{4}{|l|}{ ALT, IU/l } \\
\hline Before & $24.3 \pm 12.4$ & $29.0 \pm 14.6$ & 0.068 \\
\hline After & $23.2 \pm 12.3$ & $26.8 \pm 11.9$ & 0.137 \\
\hline \multicolumn{4}{|l|}{ ALP, IU/1 } \\
\hline Before & $83.5 \pm 25.1$ & $74.9 \pm 23.7$ & 0.065 \\
\hline After & $79.0 \pm 27.4$ & $75.2 \pm 28.4$ & 0.490 \\
\hline
\end{tabular}

Values represent mean \pm SD. ALP $=$ Alkaline phosphatase; $\mathrm{ALT}=$ alanine transaminase AST $=$ aspartate transaminase; HDL$\mathrm{C}=$ high-density lipoprotein cholesterol; LDL-C = low-density lipoprotein cholesterol.

rameters of the treatment and placebo groups at baseline and posttreatment are given in table 2 . No significant difference was observed in glycemic control between the 2 groups, demonstrated by the HbAlc values $(9.5 \pm 2.1$ vs. $8.9 \pm 2.1 \%, \mathrm{p}>0.05)$. There were no differences in other metabolic parameters measured at baseline and after treatment between the two groups.

The baseline and follow-up NSS and NDS values and the vitamin $\mathrm{D}$ status before and after treatment for both study arms are shown in table 3 . Of the 57 patients in the
Table 3. Baseline and follow-up values and comparison of differences in NSS, NDS and vitamin D status before and after treatment between the treatment and placebo groups

\begin{tabular}{lllll}
\hline Parameters & Before & After & Differences $^{1}$ p value \\
\hline NSS & & & & \\
$\quad$ Treatment & $5.92 \pm 1.29$ & $4.43 \pm 1.58$ & $-1.49 \pm 1.37$ & \\
$\quad$ Placebo & $5.50 \pm 1.25$ & $5.45 \pm 1.20$ & $-0.20 \pm 0.59$ & $<0.001$ \\
NDS & & & & \\
$\quad$ Treatment & $8.4 \pm 1.8$ & $8.4 \pm 1.8$ & $-0.42 \pm 1.59$ & 0.094 \\
$\quad$ Placebo & $7.8 \pm 1.9$ & $7.7 \pm 1.8$ & $-0.03 \pm 0.2$ & \\
25(OH)D, mmol/1 & & & & \\
$\quad$ Treatment & $25.3 \pm 10.9$ & $58.2 \pm 23.8$ & $32.8 \pm 23.7$ & $<0.0001$ \\
$\quad$ Placebo & $29.2 \pm 9.5$ & $30.3 \pm 8.9$ & $1.1 \pm 3.6$ & \\
\hline
\end{tabular}

Values represent mean \pm SD.The Mann-Whitney $U$ test was used. ${ }^{1}$ The minus sign indicates that the values decreased after treatment.

treatment group, $38(66.7 \%)$ had normal 25(OH)D levels after the treatment period. The differences in the NSS, NDS and vitamin D status before and after treatment were used to compare the effect of vitamin D supplementation between the treatment and placebo groups. The reduction in the NSS values after treatment was significantly more in the treatment group than in the placebo group $(-1.49 \pm 1.37$ vs. $-0.20 \pm 0.59, \mathrm{p}<0.001)$, while no difference was noted for the NDS. Similarly, the improvement in the serum $25(\mathrm{OH}) \mathrm{D}$ concentration after treatment was extremely significant in the treatment group compared to the placebo group $(32.8 \pm 23.7$ vs. 1.1 $\pm 3.6, \mathrm{p}<0.0001)$. The Spearman correlation did not reveal any significant correlation between change in $25(\mathrm{OH}) \mathrm{D}$ and improvement in NSS (rho $=-0.052, \mathrm{p}=$ 0.702 )

The NCS data on the latency, amplitude and conduction velocity for the motor and sensory nerves in both groups after the 8-week treatment period are given in table 4 . The baseline and follow-up results for the normal cut-off values for the peroneal and sural nerves including distal latencies, conduction velocities and amplitudes showed no statistical difference between the groups during the study period (table 5). Changes in NCS in both groups after treatment were not significant. Only 1 patient had a normal NCS result (0.89\%) after 8 weeks and 3 patients in the treatment group (2.6\%) showed an improvement after the vitamin D treatment. No changes were observed in the NCS in the placebo group. 
Table 4. NCS data including cut-off values for the treatment group and the placebo group after treatment

\begin{tabular}{|c|c|c|c|c|}
\hline & $\begin{array}{l}\text { Treatment } \\
\text { group } \\
(\mathrm{n}=57)\end{array}$ & $\begin{array}{l}\text { Placebo } \\
\text { group } \\
(\mathrm{n}=55)\end{array}$ & $\begin{array}{l}\text { Normal } \\
\text { cut-off } \\
\text { values }\end{array}$ & $\begin{array}{l}\mathrm{p} \\
\text { value }^{1}\end{array}$ \\
\hline \multicolumn{5}{|l|}{ Distal latency, mV } \\
\hline Median motor & $4.5 \pm 0.9$ & $5.4 \pm 2.4$ & $<3.7$ & 0.434 \\
\hline Median sensory & $3.1 \pm 0.4$ & $3.3 \pm 0.7$ & $<2.9$ & 0.611 \\
\hline Ulnar motor & $2.6 \pm 0.2$ & $2.7 \pm 0.1$ & $<3.2$ & 0.555 \\
\hline Ulnar sensory & $2.7 \pm 0.4$ & $2.3 \pm 0.2$ & $<3.0$ & 0.323 \\
\hline Peroneal motor & $5.2 \pm 1.0$ & $5.1 \pm 1.0$ & $<5.6$ & 0.783 \\
\hline Tibial motor & $4.9 \pm 0.6$ & $4.8 \pm 0.6$ & $<5.6$ & 0.636 \\
\hline Sural sensory & $3.3 \pm 0.2$ & $3.5 \pm 0.3$ & $<3.5$ & 0.692 \\
\hline \multicolumn{5}{|c|}{ Conduction velocity, $\mathrm{m} / \mathrm{s}$} \\
\hline Median motor & $44.0 \pm 4.9$ & $46.5 \pm 9.1$ & $>50$ & 0.214 \\
\hline Median sensory & $48.0 \pm 6.3$ & $44.0 \pm 12.7$ & $>50$ & 0.612 \\
\hline Ulnar motor & $52.0 \pm 4.3$ & $50.0 \pm 1.4$ & $>50$ & 0.784 \\
\hline Ulnar sensory & $52.8 \pm 3.4$ & $51.0 \pm 1.4$ & $>50$ & 0.522 \\
\hline Peroneal motor & $37.0 \pm 15.6$ & $42.7 \pm 11.5$ & $>40$ & 0.175 \\
\hline Tibial motor & $44.0 \pm 4.8$ & $44.0 \pm 9.6$ & $>40$ & 0.220 \\
\hline Sural sensory & $41.4 \pm 5.0$ & $39.2 \pm 3.1$ & $>40$ & 0.310 \\
\hline \multicolumn{5}{|c|}{ Motor amplitude, $\mathrm{mV}$} \\
\hline Median & $5.9 \pm 2.2$ & $5.5 \pm 4.0$ & $>5$ & 0.458 \\
\hline Ulnar & $8.5 \pm 1.7$ & $8.4 \pm 0.7$ & $>5$ & 0.958 \\
\hline Peroneal & $2.2 \pm 2.3$ & $2.8 \pm 1.9$ & $>1.5$ & 0.325 \\
\hline Tibial & $5.9 \pm 4.1$ & $6.2 \pm 3.4$ & $>5$ & 0.752 \\
\hline \multicolumn{5}{|c|}{ Sensory amplitude, $\mu \mathrm{V}$} \\
\hline Median & $17.2 \pm 3.7$ & $15.0 \pm 7.0$ & $>15$ & 0.618 \\
\hline Ulnar & $17.6 \pm 4.3$ & $20.5 \pm 0.1$ & $>15$ & 0.414 \\
\hline Sural & $5.9 \pm 2.3$ & $6.3 \pm .2 .4$ & $>9$ & 0.714 \\
\hline
\end{tabular}

Values represent mean $\pm \mathrm{SD} .{ }^{1}$ Independent-samples $t$ test.

\section{Discussion}

In this study, oral supplementation of a dose of cholecalciferol (a 50,000-IU capsule) once weekly for 8 weeks was associated with a significant improvement in the $25(\mathrm{OH}) \mathrm{D}$ concentration in the treatment group compared to placebo. The improvement in NSS was also significant in the treatment group compared to the placebo group. No improvement in NDS or NCS result was observed in either group after vitamin D supplementation.

These findings are consistent with our previous study [3] which reported vitamin $\mathrm{D}$ as an independent risk factor in peripheral neuropathy in patients with type 2 diabetes. This study has thus established that oral vitamin $\mathrm{D}$ supplementation corrects vitamin D deficiency, which leads to an improvement in the symptoms of neuropathy.

The main symptom improvement observed was in the sensation of neuropathic pain, especially burning/hyper-
Table 5. Comparison of NCS data on the peroneal and sural nerves before and after treatment in the treatment and the placebo group

\begin{tabular}{llll}
\hline $\begin{array}{l}\text { Before } \\
\text { treatment }\end{array}$ & $\begin{array}{l}\text { After } \\
\text { treatment }\end{array}$ & $\begin{array}{l}\text { Normal } \\
\text { cut-off } \\
\text { values }\end{array}$ & $\begin{array}{l}\mathrm{p} \\
\text { value }\end{array}$ \\
\hline
\end{tabular}

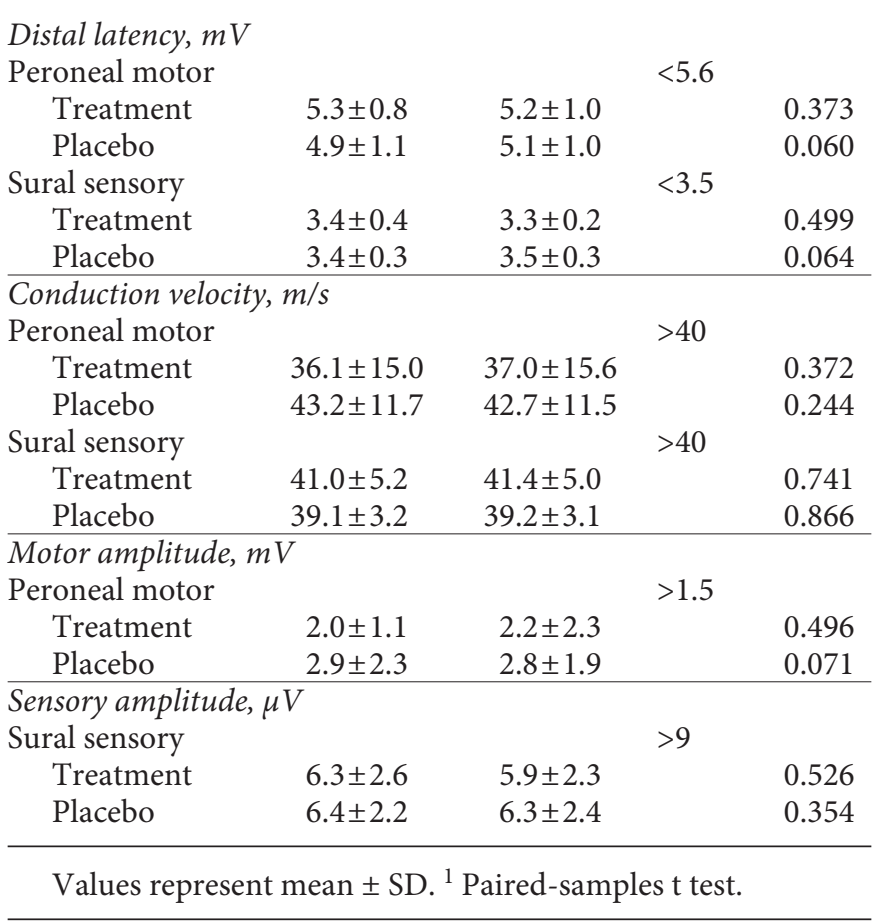

esthesia. However, it is not clear whether this was because of an elevation of pain threshold or due to an improvement in the function of the affected nerves, or both $[7,18]$. Vitamin $\mathrm{D}$ is a potent inducer of neurotrophins and neurotransmitters; the biological effect of vitamin D on the nervous system includes the biosynthesis of enzymes involved in neurotransmitter synthesis as well as substances involved in brain detoxification pathways. The addition of vitamin $\mathrm{D}$ potentiates the nerve growth factor (NGF), a protein required for the development and maintenance of several populations of neurons in the peripheral nervous system [19]. In animal studies, it has been shown that the addition of vitamin $\mathrm{D}_{3}$ analogs potentiates the reversal of the neurotrophic deficits of diabetes $[20,21]$. However, the mechanisms to explain the observed symptomatic improvement in humans are yet to be elucidated. It has been reported that vitamin D analogs are also effective in inducing NGF in human cell lines $[22,23]$. In the skin, epidermal keratinocytes are the primary source of NGF and decreased NGF in patients with diabetic polyneuropathy correlates with neuropath- 
ic indicators of sensory and autonomic nerve function [23].

No significant changes were observed in NDS (ankle reflex, pinprick or vibration), probably due to an inadequate dose or duration of supplementation or both. The majority of our patients did not show an improvement in NCS with treatment. This could also be due to the underlying pathophysiology of peripheral neuropathy in diabetes, since the duration of diabetes in our patients was prolonged (years) and the pathophysiology of neuropathy could be mainly axonal; it takes longer than 8 weeks for nerves to be regenerated or to correct the effects of an absence of vitamin $\mathrm{D}$.

Only $1(0.89 \%)$ patient had a normal NCS result after 8 weeks and 3 (2.6\%) showed an improvement after treatment, observed in the motor conduction velocity of the peroneal and tibial nerves and the sensory conduction velocity in the sural nerves. The NCS was conducted by the same clinician using the same machine and standard techniques, so the likelihood of technical bias was reduced. Interestingly enough, in animal models of diabetes [21], no changes were observed in the motor or sensory conduction velocities after 8 weeks of treatment with a vitamin $\mathrm{D}_{3}$ derivative. It is, therefore, tempting to speculate that the human and animal experimental findings were comparable. The effects observed in this study were not biased by any changes in glycemic control, since no significant differences were noted between the treatment and placebo groups in $\mathrm{HbA} 1 \mathrm{c}$ before or after treatment.

A randomized, placebo-controlled, double-blind study [5] that used a topical cream containing vitamin $\mathrm{D}_{3}$ in 34 type 1 and type 2 diabetic patients led to an improvement in symptoms and quality of life. In a study by Lee and Chen [6], 51 type 2 diabetic patients with neuropathic pain and vitamin D deficiency were treated with oral vitamin $\mathrm{D}_{3}$, and then reevaluated after 3 months. They showed an improvement on a visual analog scale. The most recent similar account was a case report by Bell [7], where oral vitamin $\mathrm{D}$ supplementation, even in a type 1 diabetic patient, led to a dramatic improvement in neuropathic symptoms.

The main limitation of this study was the nonrandomization of the selection of patients. However, there were also several strengths: it was a prospective, placebo-controlled, double-blind study with a large sample. Two previously validated neuropathic scores, namely the NSS and NDS as primary outcome measures and an NCS as a secondary outcome measure, were used.

\section{Conclusions}

This study showed that short-term oral supplementation of vitamin $\mathrm{D}$ to correct a deficiency improved the symptoms of peripheral neuropathy in patients with type 2 diabetes. We recommend conducting randomized, controlled trials in order to explore, prospectively, the issues of proper dosing as well as the route and duration of treatment, to confirm the efficacy and clinical benefits of vitamin D supplementation on DPN.

\section{Acknowledgement}

We would like to thank Dr. Mini Abraham Puliyelil for technical assistance.

\section{Disclosure Statement}

The authors have no conflicts of interest to disclose.

\section{References}

\footnotetext{
1 Edwards JL, Vincent AM, Cheng HT, et al: Diabetic neuropathy: mechanisms to management. Pharmacol Ther 2008;120:1-34.

2 Chaychi L, Mackenzie T, Bilotta D, et al: Association of serum vitamin $\mathrm{D}$ level with diabetic polyneuropathy. Med Pract Rev 2011;2: $11-15$.

-3 Shehab D, Al-Jarallah K, Mojiminiyi OA, et al: Does vitamin D deficiency play a role in peripheral neuropathy in type 2 diabetes? Diabet Med 2012;29:43-49.

4 Soderstrom LH, Johnson SP, Diaz VA, et al: Association between vitamin $\mathrm{D}$ and diabetic neuropathy in a nationally representative sample: results from 2001-2004 NHANES. Diabet Med 2012;29:50-55.
}

5 Valensi P, Devehat C, Richard J, et al: A multicenter double blind, safety study of QR-333 for the treatment of symptomatic diabetic peripheral neuropathy: a preliminary report. J Diabetes Complications 2005; 19:247-253.

6 6 Lee P, Chen R: Vitamin D as an analgesic for patients with type 2 diabetes and neuropathic pain. Arch Intern Med 2008;168:771-772.

7 Bell DS: Reversal of the symptoms of diabetic neuropathy through correction of vitamin $\mathrm{D}$ deficiency in a type 1 diabetic patient. Case Rep Endocrinol 2012;2012:165056.

-8 Standards of Medical Care in Diabetes 2013. Diabetes Care 2013;36(suppl 1):S11-S66. 
9 Young MJ, Boulton AJ, Macleod AF, et al: A multicenter study of the prevalence of diabetic peripheral neuropathy in the United Kingdom hospital clinic population. Diabetologia 1993;36:150-154.

10 Abbott CA, Carrington AL, Ashe H, et al: The North-West Diabetes Foot Care Study: incidence of, and risk factors for, new diabetic foot ulceration in a community-based patient cohort. Diabet Med 2002;19:377-384.

11 Malik RA, et al: Corneal confocal microscopy: a non-invasive surrogate of nerve fibre damage and repair in diabetic patients. Diabetologia 2003;46:683-688.

12 Kimura J: Principles of nerve conduction studies; in Kimura J (ed): Electrodiagnosis in Diseases of Nerve and Muscle: Principles and Practice, ed 2. Philadelphia, Davis, 1989, pp 78-102.

13 Kimura J: Principles and pitfalls of nerve conduction studies. Ann Neurol 1984;16:415428.
4 Shehab D: Normative DATA of nerve conduction studies in the upper limb in $\mathrm{Ku}$ wait - are they different than the Western data? Med Princ Pract 1998;7:203-208.

15 Shehab D, Moussa MA: Normal values of lower limb nerve conduction in Kuwait. II. Med Princ Pract 1999;8:134-137.

16 Adams JS, Hewison M: Update in vitamin D. J Clin Endocr Metab 2010;95:471-478.

17 Holick MF, Binkley N, Bischoff-Ferrari HA, et al: Evaluation, treatment, and prevention of vitamin D deficiency: an Endocrine Society clinical practice guideline. J Clin Endocrinol Metab 2011;96:1911-1930.

18 Plotnikoff GA, Quigley JM: Prevalence of severe hypovitaminosis $\mathrm{D}$ in patients with persistent, nonspecific musculoskeletal pain. Mayo Clin Proc 2003;78:1463-1470.
9 Carlson AN, Kenny AM: Is vitamin D insufficiency associated with peripheral neuropathy? Endocrinologist 2007;17:319-325.

20 Neveu I, Jehan F, Wion D: Alteration in the levels of $1,25-(\mathrm{OH}) 2 \mathrm{D}_{3}$ and corticosterone found in experimental diabetes reduces nerve growth factor (NGF) gene expression in vitro. Life Sci 1992;50:1769-1772.

21 Riaz S, Malcangio M, Miller M, et al: A vitamin $\mathrm{D}_{3}$ derivative (CB1093) induces nerve growth factor and prevents neurotrophic deficits in streptozocinp diabetic rats. Diabetologia 1999;42:1308-1313.

22 Fukuoka M, Sakurai K, Ohta T, et al: Tacalcitol, an active vitamin $\mathrm{D}_{3}$, induces nerve growth factor production in human epidermal keratinocytes. Skin Pharmacol Appl Skin Physiol 2001;14:226-233.

23 Anand P, Terenghi G, Warner G, et al: The role of endogenous nerve growth factor in human diabetic neuropathy. Nat Med 1996;6: 703-707. 